\title{
A Benchmark Analytical Solution for Landslide Tsunamis
}

\author{
Baran Aydın ${ }^{1 *}$

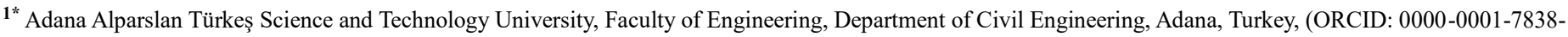
3708), baydin@atu.edu.tr

(First received 18 February 2021 and in final form 3 August 2021)

(DOI: 10.31590/ejosat.882503)

ATIF/REFERENCE: Aydın, B. (2021). A Benchmark Analytical Solution for Landslide Tsunamis. European Journal of Science and Technology, (25), 697-701.

\begin{abstract}
An analytical solution is developed to model propagation of tsunami waves generated by underwater landslides. The proposed solution could particularly be used for validation of experimental and numerical models, since it allows imposition of block-type bottom profiles. Tsunami run-up, that is, time series of water elevations at the initial shoreline, and its maximum is calculated through the proposed analytical model. Effects of steepness of the bottom profile and slide length on the maximum run-up are also analyzed.
\end{abstract}

Keywords: Landslide, Tsunami, Analytical model, Maximum run-up, Benchmark solution.

\section{Heyelan Sonucu Meydana Gelen Tsunamiler İçin Kıstas Bir Analitik Çözüm}

$\ddot{O} \mathbf{z}$

Denizaltı heyelanları sonucu meydana gelen tsunami dalgalarının yayılımlarının modellenmesi için bir analitik çözüm geliştirilmiştir. Önerilen çözüm blok tipi taban profillerinin uygulanmasına imkân verdiği için özellikle deneysel ve sayısal modellerin doğrulanması için kullanılabilecektir. Tsunami tırmanması, yani kıyı çizgisindeki dalga yüksekliğinin zaman serisi ve maksimum tırmanma önerilen analitik model aracılığıyla hesaplanmıştır. Taban profilinin dikliğinin ve uzunluğunun maksimum tırmanma üzerindeki etkileri de ayrıca incelenmiştir.

Anahtar Kelimeler: Heyelan, Tsunami, Analitik model, Maksimum tırmanma, Kıstas çözüm.

\footnotetext{
* Corresponding Author: baydin@atu.edu.tr
} 


\section{Introduction}

Documentation of historical tsunami events indicate the role of landslides as a secondary mechanism after earthquakes (Gusiakov, 2009). Many laboratory-scale physical model studies are performed in order to understand the characteristics of landslide-generated ocean waves.

Laboratory studies of landslide-generated waves date back to more than half a century. Notable studies are performed by Bowering (1970), Das and Wiegel (1972) and Kamphuis and Bowering (1970), although none of them focused on parameters controlling the characteristics of waves in the near field.

Significant progress has been made recently in experimental work, following developments in computers, laboratory equipment and image processing techniques. Walder et al. (2003) predicted near-field amplitude, wavelength, and submerged travel time for landslides through block-type models. Trifunac et al. (2003) developed an analytical model for composite rectangular blocks moving horizontally and provided good near-field estimations for slides moving with long wave velocity.

Di Risio and Sammarco (2003) modeled transient waves by fall of a block into water vertically, and validated their experimental results with a linear analytical solution. Panizzo et al. (2005) carried out experimental work in order to define empirical formulations able to forecast the principal features of waves generated by subaerial landslides falling into threedimensional reservoirs as a function of landslide parameters. They also utilized a rectangular block model in their experiments.

More recently, Heller and Spinneken (2013) used a rectangular block landslide model and investigated, for the first time in the literature, the role of the blockage ratio (i.e. ratio of the slide width to the channel width), the slide front angle and the slide transition type at the toe of the slope on the wave pattern.

Other notable experimental studies in the field are carried out by Watts (1998, 2000), Fritz et al. (2004), Watts et al. (2005), Lynett and Liu (2005), Di Risio et al. (2009), Fuchs et al. (2013), Heller and Spinneken (2015) and Romano et al. (2016).

The common feature of most experimental landslide models, including those listed above, is that they simulate the sliding mass as solid blocks. The widely used slide geometries are rectangular blocks (having vertical sides), trapezoidal blocks (usually with one inclined side) and wedges (having triangular cross-sections).

We therefore focused in this study on an analytical model that can be used as benchmark for either experimental or numerical landslide tsunami models employing block-type slide geometry. We developed a linear analytical solution based on the shallowwater wave theory and we investigated the role of certain slide parameters on the maximum run-up of tsunami waves generated by block-type displacement of sea bottom.

\section{Material and Method}

\subsection{General Analytical Solution}

The number of studies offering analytical solutions to subsequent modeling of landslide-generated tsunamis is limited, even in one horizontal dimension. This is due to the complexity of the problem, both from physical and mathematical points of view. The sliding mass at the sea bottom makes the water depth a function of time, which, in turn, makes the continuity equation nonhomogeneous. Consequently, an initial value problem with a nonhomogeneous governing partial differential equation needs to be solved.

A remarkable contribution in the field is the analytical solution proposed long ago by Tuck and Hwang (1972). Incorporating the sliding sea floor as a small time-dependent perturbation on a uniform slope, they quantified propagation of the resulting waves through the linear shallow-water wave equations (LSWE) written in one space dimension.

Three decades later, Liu et al. (2003) revisited Tuck and Hwang (1972)'s analytical solution and presented results for bottom forcing having a small vertical thickness compared to its horizontal length. They elegantly defined a particular solution in terms of the bottom disturbance, which allows different functions to be imposed, although they provided results only for the socalled Gaussian bottom disturbance.

We follow Liu et al. (2003) here and simulate the prescribed time-dependent bottom perturbation sliding on a constant slope using the LSWE, they reformulated which as

$$
\eta_{t t}-\frac{\tan \beta}{\mu}\left(x \eta_{x}\right)_{x}=h_{t t}
$$

In this equation the unknown function is the free surface height $\eta(x, t) . h(x, t)$ is a given time-dependent bottom perturbation, while $x$ and $t$ are space and time variables, respectively (Figure 1). Also, $\beta$ represents beach angle with the horizontal and $\mu$ stands for the slide mass ratio, i.e. the ratio of the vertical thickness $(\delta)$ to the horizontal length of the slide $(L)$. We also note that eq.(1) remains valid for thin slides, i.e. $\mu \ll 1$.

Eq.(1) will be subjected to the following initial conditions:

$$
\eta(x, 0)=0, \eta_{t}(x, 0)=h_{t}(x, 0)
$$

which define an undisturbed initial sea state with zero initial fluid velocity.

Liu et al. (2003) suggested the replacement of the space variable $(x)$ by

$$
\xi=2 \sqrt{\mu x /(\tan \beta)}
$$

so that the governing equation (1) can be converted into a Besseltype equation:

$$
\eta_{t t}-\frac{1}{\xi}\left(\xi \eta_{\xi}\right)_{\xi}=h_{t t}
$$

Since eq.(2) is nonhomogeneous, its complete solution will have the structure $\eta(\xi, t)=\eta_{h}(\xi, t)+\eta_{p}(\xi, t)$; where $\eta_{h}$ and $\eta_{p}$ are the homogeneous and the particular solutions, respectively.

Moreover, Liu et al. (2003) managed to define the particular solution $\left(\eta_{p}\right)$ in terms of the bottom perturbation $(h)$ in the following way:

$$
\eta_{p}(\xi, t)=\frac{1}{3}\left[h(\xi, t)-\xi h_{\xi}(\xi, t)\right]
$$




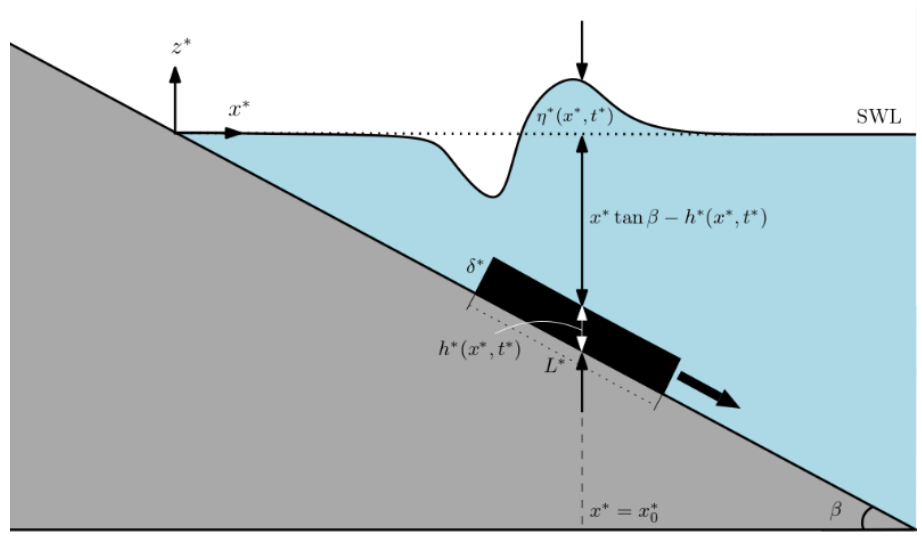

Figure 1. Definition sketch for the landslide problem. Not to scale.

The reader is referred to Liu et al. (2003) for the details of the solutions $\eta_{h}$ and $\eta_{p}$. Eq.(3) is a very useful particular solution since it allows use of different bottom profiles, $h(\xi, t)$. Although Liu et al. (2003) presented results only for the so-called Gaussiantype sea floor deformation, $h(\xi, t)=\exp \left(-(\xi-t)^{2}\right)$, Aydin (2021) verified that eq.(3) becomes a particular solution of eq.(2) for any disturbance with the property $h(\xi, t)=F(\xi-a-t)$.

\subsection{Rectangular-type bottom profiles}

We now offer a new bottom perturbation

$$
\begin{aligned}
h_{e}(\xi, t)=\frac{\delta}{2}[\operatorname{erf}( & p(\xi-a-t)) \\
& -\operatorname{erf}(p(\xi-a-L-t))]
\end{aligned}
$$

which is defined through the error function

$$
\operatorname{erf}(z)=\frac{2}{\sqrt{\pi}} \int_{0}^{z} \exp \left(-t^{2}\right) d t
$$

The profile defined in eq.(4) occupies a length $L$ in the horizontal and a height $\delta$ in the vertical. The parameter $a$ is introduced so that the sliding mass can be located at any desired point on the slope, while the parameter $p$ is used to be able to change the steepness of the profile. Since this profile displaces the sea bottom like a rectangular box (as seen in the top panels of Figure 2 and 3 ), a prototype usually used to represent sliding masses in laboratory-scale physical models, analytical model results from this profile can be used for benchmarking of experimental results in particular. To the best of author's knowledge, there is no such study aiming to provide an analytical solution for validation of physical models using block type bottom disturbances with a rectangular or trapezoidal cross sections.

In the next section we present and discuss run-up results obtained for the bottom disturbance defined in eq.(4).

\section{Results and Discussion}

We calculated run-up of subsequent waves triggered by the motion the sea bottom profile given in eq.(4). We varied the steepness $(p)$ and the length $(L)$ of the profile and investigated the relationship of the maximum tsunami run-up with these parameters. We performed calculations for a beach slope angle of $\beta=5^{\circ}$, an initial slide submergence of $a=5$ and a slide thickness of $\delta=0.2$. We selected $L$ in such a way that the slide aspect ratio $\mu=\delta / L$ is small and the linear theory is applicable.
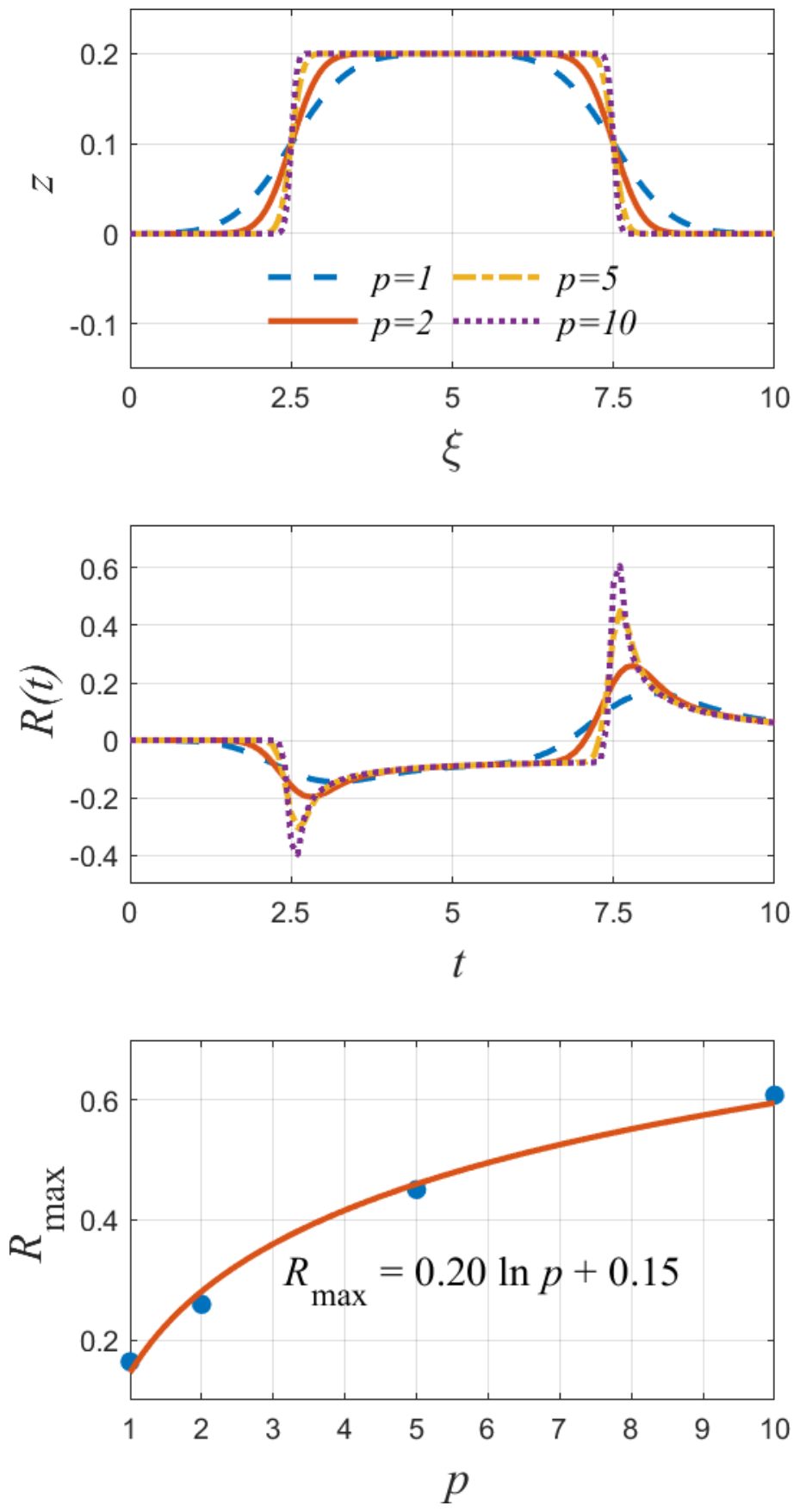

Figure 2. (top) The bottom disturbance defined in eq.(4) is plotted for $L=5$ and four different values of the steepness parameter ( $p)$. (middle) The variation of tsunami run-up with time is plotted for the selected values of $p$. (bottom) The functional relationship of the maximum tsunami run-up with the steepness parameter is demonstrated.

We first examined the effect of the steepness parameter $\boldsymbol{p}$ on the maximum run-up. For this purpose, we fixed the slide parameters other than $\boldsymbol{p}$ and plotted the run-up variation with time for $\boldsymbol{p}=\mathbf{1}, \mathbf{2}, \mathbf{5}$ and $\mathbf{1 0}$. The slide length is selected as $\boldsymbol{L}=\mathbf{5}$, so that $\boldsymbol{\mu}=\mathbf{0 . 0 4}$. As seen in the top panel of Figure 2, the bottom profile becomes steeper and resembles a rectangular block as $\boldsymbol{p}$ increases.

Increase in $p$ also reflects as a significant change in the runup $R(t)=\eta(x, t=0)$, as seen in the middle panel, and its maximum over time, $R_{\max }=\max \{R(t)\}$, as seen in the bottom panel of Figure 2. A curve-fitting procedure is used in order to 
reveal the relationship between $R_{\max }$ and $p$. The data suggested a relation of the form

$$
R_{\text {max }}=A_{1} \ln p+B_{1}
$$

and the coefficients are found, with coefficient of determination $R^{2}=0.99$, as $A_{1}=0.20$ and $B_{1}=0.15$.

Further, in Figure 3, we changed the slide length from $L=2$ to $L=5$, so that $0.04 \leq \mu \leq 0.1$ (the top panel shows profiles with different lengths), and plotted time variation of the run-up for a slide steepness of $p=5$. Increase in $L$ reflects as an increase in the run-up $R(t)$, as seen in the middle panel. Moreover, a linear increase in the maximum run-up $R_{\max }$ is observed (bottom panel). A curve-fitting procedure for a linear relationship

$$
R_{\text {max }}=A_{2} L+B_{2}
$$

yielded the values $A_{2}=0.03$ and $B_{2}=0.30$, with $R^{2}=0.99$, for the coefficients. We remark that dimensionless variables are used in the foregoing analysis.

\section{Conclusions and Recommendations}

We suggested a linear analytical model for propagation and run-up of landslide generated tsunami waves, which is particularly suitable for validation of experimental results, as it is able to simulate block-type bottom disturbances.

We calculated wave run-up and its maximum for two different parameter sets. Fixing the other slide parameters, the slide steepness is varied in the first set, while the slide length is changed in the second.

Results indicate a logarithmic relationship between the maximum run-up and the steepness parameter. Furthermore, there is a slight change in the instant when the maximum run-up is observed. This is to be expected, since the initial submergence and the length of the slide are the same and its steepness is varied only.

On the other hand, it is seen that the maximum run-up increases linearly with the slide length. Also, the time when runup assumes its maximum changes significantly as the slide length is changed.

The proposed model apparently has certain limitations; dispersive effects and slide deformations are neglected. Also, nonlinear effects are assumed to be small, although it is shown to be an adequate assumption, for larger $(\tan \beta) / \mu$ in particular (Liu et al., 2003). In spite of these restrictions, the analytical model proposed here remains as a powerful tool for benchmarking of experimental and numerical studies. As Liu et al. (2003) comment, “... analytical solutions are invaluable in helping validate computational techniques and in establishing relevant dimensionless scales such as $(\tan \beta) / \mu$."

For future work, the results obtained from the analytical solution can be compared with experimental results. The effect of other landslide parameters on the maximum run-up can also be investigated.
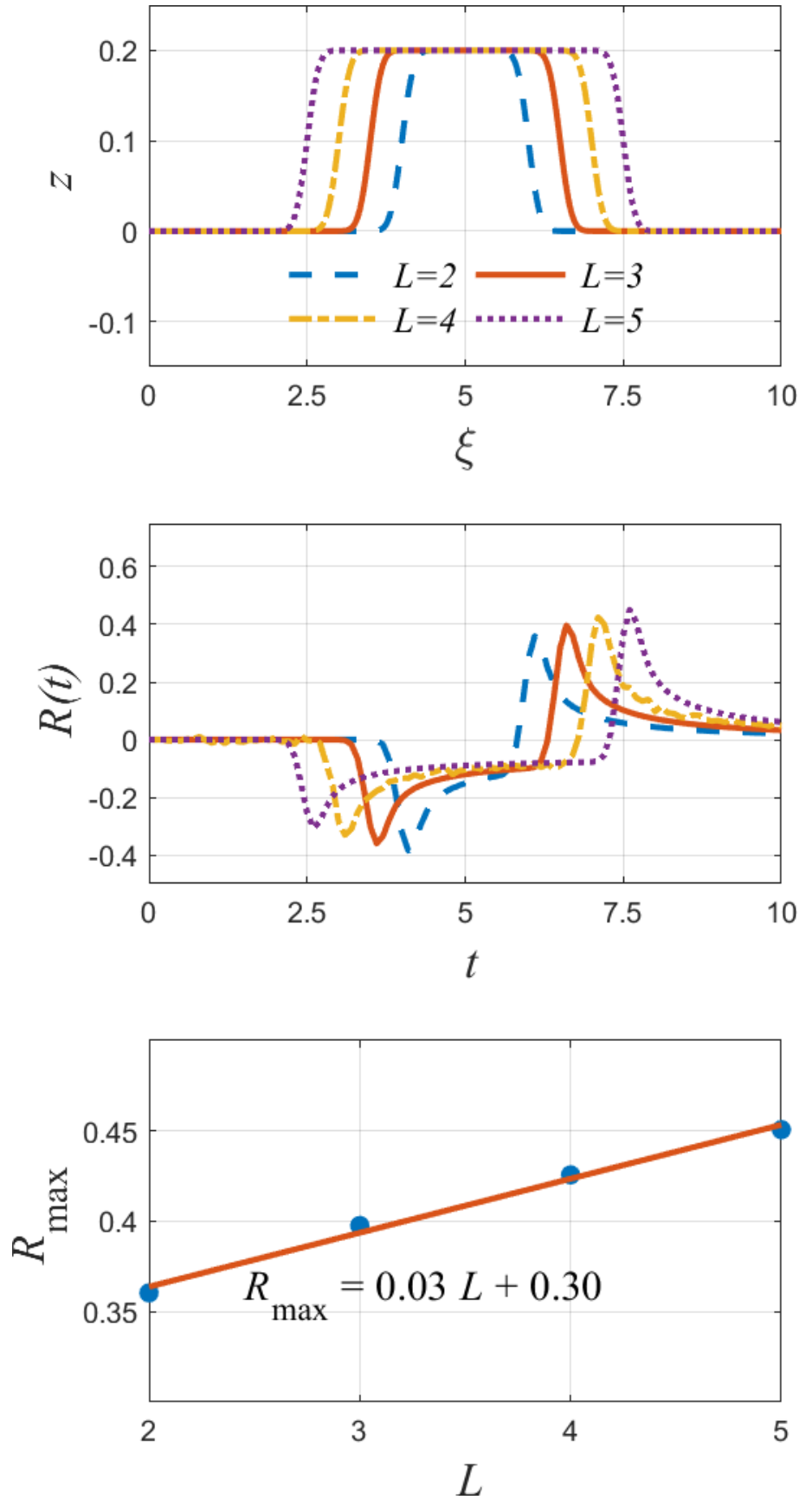

Figure 3. (top) The bottom disturbance defined in eq.(4) is plotted for $p=5$ and four different values of the slide length (L). (middle) The variation of tsunami run-up with time is plotted for the selected values of L. (bottom) The functional relationship of the maximum tsunami run-up with the slide length is demonstrated.

\section{References}

Aydın, B. (2021). An analytical study on tsunami run-up due to submarine landslides from different bottom profiles. Afyon Kocatepe University Journal of Science and Engineering, 21(2), 426-433.

Bowering, R. J. (1970). Landslide generated waves: a laboratory study. Master's thesis, Queen's University, Kingston, Ontario, Canada. 
Das, M. M. and Wiegel, R. L. (1972). Waves generated by horizontal motion of a wall. J. Waterw. Harbors Coastal Eng. Div. Am. Soc. Civ. Eng., 98, 49-65.

Di Risio, M., Bellotti, G., Panizzo, A., and De Girolamo, P. (2009). Three-dimensional experiments on landslide generated waves at a sloping coast. Coastal Engineering, 134, 53-60.

Di Risio, M. and Sammarco, P. (2003). Analytical modeling of landslide-generated waves. Journal of Waterway, Port, Coastal, and Ocean Engineering, 134, 53-60.

Fritz, H. M., Hager, W. H., and Minor, H.-E. (2004). Near field characteristics of landslide generated impulse waves. Journal of Waterway, Port, Coastal, and Ocean Engineering, 130 (6), 287-302.

Fuchs, H., Winz, E., and Hager, W. H. (2004). Underwater landslide characteristics from 2D laboratory modeling. Journal of Waterway, Port, Coastal, and Ocean Engineering, 139(6), 480-488.

Heller, V. and Spinneken, J. (2015). On the effect of the water body geometry on landslide tsunamis: Physical insight from laboratory tests and $2 \mathrm{D}$ to $3 \mathrm{D}$ wave parameter transformation. Coastal Engineering, 104(118), 113-134.

Heller, V. and Spinneken, J. (2013). Improved landslide-tsunami prediction: Effects of block model parameters and slide model. Journal of Geophysical Research: Oceans, 118, 1489-1507.

Kamphuis, J. W., and R. J. Bowering. (1970). Impulse waves generated by landslides, In Proceedings of $11^{\text {th }}$ Coastal Engineering Conference, 575-588.

Liu, P. L.-F., Lynett, P., and Synolakis, C. E. (2003). Analytical solutions for forced long waves on a sloping beach. Journal of Fluid Mechanics, 478, 101-109.

Lynett, P. and Liu, P. L.-F. (2005). A numerical study of the runup generated by three-dimensional landslides. Journal of Geophysical Research, 110, C03006.

Panizzo, A., De Girolamo, P., and Petaccia, A. (2005). Forecasting impulse waves generated by subaerial landslides. Journal of Geophysical Research, 110, C12025.

Romano, A., Di Risio, M., Bellotti, G., Molfetta, G., Damiani, L., and De Girolamo, P. (2016). Tsunamis generated by landslides at the coast of conical islands: Experimental benchmark dataset for mathematical model validation. Landslides, 13(6), 1379-1393.

Trifunac, M. D., Hayir, A., and Todorovska, M. I. (2003). A note on tsunami caused by submarine slides and slumps spreading in one dimension with nonuniform displacement amplitudes. Soil Dynamics and Earthquake Engineering, 23, 223-234.
Tuck, E. O. and Hwang, L. S. (1972). Long wave generation on a sloping beach. Journal of Fluid Mechanics, 51, 449-461.

Walder, J. S., Watts, P., Sorensen, O. E., and Janssen, K. (2003). Tsunamis generated by subaerial mass flows. Journal of Geophysical Research, 108, No. B5, 2236.

Watts, P. (1998). Wavemaker curves for tsunamis generated by underwater landslides. Journal of Waterway, Port, Coastal, and Ocean Engineering, 124, 127-137.

Watts, P., Grill, S. T., Tappin, D. R., and Fryer, G. J. (1998). Tsunami generation by submarine mass failure II: Predictive equations and case studies. Journal of Waterway, Port, Coastal, and Ocean Engineering, 131(6), 298-310. 